\title{
Re-oxygenation causes hypoxic tumor regression through restoration of p53 wild-type conformation and post-translational modifications
}

\author{
R Gogna ${ }^{1}$, E Madan ${ }^{1}$, P Kuppusamy ${ }^{2}$ and U Pati ${ }^{\star, 1}$
}

Hypoxic tumors are resistant to conventional therapies through indirect mechanisms such as the selection of resistant phenotype under chronic hypoxia. Hyperbaric oxygen (HBO) therapy has been shown to increase oxygen level and induce apoptosis in hypoxic tumor. However, it could produce significant adverse effects including oxygen toxic seizures and severe radiation tissue injury due to high pressure. We have shown that repeated oxygenation at $30 \% \mathrm{O}_{2}$ ( 1 atmospheres absolute) results in significant regression of MCF-7 tumor xenografts without any adverse effect. In MCF-7 cells, re-oxygenation showed an eightfold increase in cellular apoptosis. Both in hypoxic tumor and in hypoxic cells, that exclusively favor p53 to exist in mutant conformation, re-oxygenation restores p53 wild-type conformation. The oxygen-mediated rescue of mutant p53 followed by its trans-activation is responsible for the induction of p53-downstream apoptotic, cell-cycle arrest and DNA-repair genes. Further, p53 trans-activation may thus be due to its post-translational modifications as a result of re-oxygenation. We have thus concluded that oxygen therapy without pressure, as opposed to HBO therapy, may be ideal for hypoxic tumor regression, which functions through oxygen-mediated rescue of mutant p53 followed by induction of apoptosis.

Cell Death and Disease (2012) 3, e286; doi:10.1038/cddis.2012.15; published online 15 March 2012

Subject Category: Cancer

Hypoxia is a physiological phenomenon commonly observed in solid tumors, because oxygen levels fluctuate in the tumor microenvironment. Tumor hypoxia is associated with increased invasion and metastatic potential thus making tumor cells resistant to conventional therapy. Hyperbaric oxygen (HBO) therapy, ${ }^{1-3}$ a process that is characterized by induced apoptosis, reduced vascular density and changes in gene expression, was shown to increase $\mathrm{pO}_{2}$ levels in a rat model causing significant reduction in tumor growth, ${ }^{4}$ by downregulating STAT3 and cyclin-D1 expressions. ${ }^{5}$ However, hyperoxia as a result of $\mathrm{HBO}$ also produces reactive oxygen species, which increase sensitivity to seizures in rats including severe radiation tissue injury; probably through nitric oxide synthase activation. ${ }^{6,7}$ On the contrary, apoptosis was significantly suppressed in an inversely dose-dependent manner at partial oxygen pressures below $10 \%$ in spermatocytes and spermatids. $^{8}$

Hypoxia is known to modulate the p53 pathway, in a manner dependent or not of hypoxia induction factor-1, the severity and the duration of hypoxia influence p53 protein level and activity, in a cell-specific manner. ${ }^{9}$ Cellular responses to DNA-damage after hypoxia and re-oxygenation in cultured human lymphocytes show that re-oxygenation following hypoxia activates DNA-damage checkpoint signalling pathways that suppress cell-cycle progression inducing p53 expression and phosphorylation ${ }^{10}$ of $p 53$ at the serine15 residue. Further, oxygen induces $S$-phase growth arrest and increases $\mathrm{p} 53$ and $\mathrm{p} 21^{\mathrm{WAF} 1 / \mathrm{CIP} 1}$ expression in human bronchial smooth-muscle cells leading to oxygen-mediated alterations in proliferation are time- and concentrationdependent manner. ${ }^{11}$ Hypoxia-induced p53 fails to transactivate its target genes; recently, we have established that the cause of its non-functional status in hypoxic tumor is due to its conformational change under low oxygen concentration. Strikingly, WT p53 behaves as a molecular chaperone and rescued mutant p53 in hypoxic tumors thus causing hypoxic tumor regression. ${ }^{12}$

As the selection of p53-defective cells has been described as a consequence of cyclic hypoxia ${ }^{13}$ and Wt p53 undergoes conformational change in to mutant form under low oxygen concentration, we asked if re-oxygenation at normobaric pressure could trans-activate $\mathrm{p} 53$ and its downstream genes in regressing of hypoxic tumor. In this study, we have shown that re-oxygenation (30\%, 1 atmospheres absolute (ATA)) resulted in a significant regression of MCF-7 tumor xenografts through p53-mediated apoptosis. Re-oxygenation restored p53 wild-type conformation followed by activation of its downstream genes in the hypoxic cancer cells. We conclude that the p53 trans-activation may be due to oxygen-dependent p53 post-translational modifications.

\section{Result}

Oxygenation induces apoptosis and tumor regression in p53 $(+I+)$ hypoxic cancer cells. The degree of hypoxia

\footnotetext{
${ }^{1}$ Transcription and Human Biology Laboratory, School of Biotechnology, Jawaharlal Nehru University, New Delhi, India and ${ }^{2}$ Department of Internal Medicine, Davis Heart and Lung Research Institute, The Ohio State University, Columbus, OH, USA

${ }^{*}$ Corresponding author: U Pati, Transcription and Human Biology Laboratory, School of Biotechnology, Jawaharlal Nehru University, JNU Campus, New Delhi 110067, India. Tel: + 91 9312401811; Fax: + 9111 26783456; E-mail: Uttam @mail.jnu.ac.in

Keywords: p53; hypoxia; tumor regression; oxygenation; mutant rescue

Abbreviations: HBO, hyperbaric oxygen; ATA, atmospheres absolute; EPR, electron paramagnetic resonance

Received 14.11.11; revised 30.1.12; accepted 31.1.12; Edited by A Finazzi Agró
} 
in tumors is highly variable, with the $\mathrm{PO}_{2}$ generally $<10-30 \mathrm{~mm} \mathrm{Hg}\left(1-3 \% \quad \mathrm{O}_{2}\right)$, in contrast to a $\mathrm{PO}_{2}$ of $50-80 \mathrm{~mm} \mathrm{Hg}$ in most normal tissues. ${ }^{14}$ Lithium octa-n-butoxy2,3-naphthalocyanine ( $\mathrm{LiNc}-\mathrm{BuO}$ ) microcrystals were used for tissue oxygen measurements in MCF-7 tumor xenografts in healthy nude mice by electron paramagnetic resonance (EPR) oximetry. The hypoxic core region has $1.8 \mathrm{~mm} \mathrm{Hg} \mathrm{O}_{2}$ concentration $\left(\mathrm{pO}_{2}\right)$ whereas the healthy (non-tumor) tissue showed $21.2 \mathrm{~mm} \mathrm{HgO}_{2}$ (Figure 1a). ${ }^{12}$ In order to determine the minimal oxygen concentration (1 ATA) that might induce highest degree of apoptosis in hypoxic MCF-7 cancer cells, we exposed cells to hypoxia $\left(1.8 \% \mathrm{O}_{2}, 72 \mathrm{~h}\right)$ followed by re-oxygenation at different $\mathrm{O}_{2}$ concentrations (10-100\%) and measured apoptosis (Figure 1b). The apoptotic profile of these re-oxygenated cells was analyzed by annexin $\mathrm{V}$ staining. Re-oxygenation induced $64 \%$ apoptosis in p53 $(+/+)$ MCF-7 cells between the oxygen range of 30 and $100 \%$ oxygen when compared with $45 \%$ cellular apoptosis at $20 \% \mathrm{O}_{2}$. Further $10 \% \mathrm{O}_{2}$ induced a mere $8 \%$ apoptosis in hypoxic MCF-7 cells (Figure 1c). The results showed that $30 \%$ oxygen treatment induced eightfold increase in cellular apoptosis in the hypoxic MCF-7 cells. The effect of oxygen (re-oxygenation) on cellular apoptosis was then analyzed in several cell lines with p53 $(+/+)$ and $(-/-)$ status. Interestingly, the induction of oxygendependent apoptosis was exclusively higher in p53+I+ (HepG2, 61\%; UOS2, 59\%; RKO, 65\%) cells (Figure 1d). On the other hand, the apoptosis in response to $\mathrm{O}_{2}$ in p53-/- (Saos-2 and H1299) and p53 mutant cells (PC3 p53, HeLa p53, DU145 p53, WRO, Lncap, T47D) was substantially lower (8-18\%) (Figure 1d), suggesting that the observed oxygen-mediated apoptosis is p53 dependent. In order to confirm the role of p53 in re-oxygenation-induced apoptosis in hypoxic cancer cells we used MCF-7 p53 $(+/+$ and $-/-)$ and HCT p53( $+/+$ and $-/-)$ system as described previously by Gogna et al. ${ }^{15}$ The results shows that the apoptosis observed in MCF-7 p53 $(+/+)$ and HCT p53 $(+/+)$ cells was significantly high as compared with the MCF-7 p53(-/-) and HCT p53(-/-) cells (Figure 1e). It is thus suggested that re-oxygenation-induced apoptosis in hypoxic cancer cells is dependent on the presence of Wt p53 in these cells.

The observed role of oxygen in apoptosis in p53 $(+/+)$ cancer cells led us to study the regression of hypoxic MCF-7 p53 $(+/+)$, MCF-7 p53 $(-/-)$, HCT p53 $(+/+)$ and HCT p53(-/-) tumors through re-oxygenation. The tumor xenografts were grown on the hind leg of nude mice and the tumors were treated with cisplatin for 20 days as control. The mice bearing tumors were then exposed to $50 \% \mathrm{O}_{2}, 1$ ATA, for $3 \mathrm{~h}$ per day for 20 days. The results showed that re-oxygenation induced $77 \%$ and $80 \%$ tumor regression in MCF-7 p53 $(+/+)$ and HCT p53 $(+/+)$ tumors, whereas only $23 \%$ and $20 \%$ tumor regression was observed in re-oxygenated MCF-7 p53(-/-) and HCT p53(-/-) tumors, respectively (Figure 2a). These data establish the crucial role of p53 in tumor regression via re-oxygenation. We further analyzed if the tumor regression in hypoxic tumors was due to induction of apoptosis in the tumor xenografts using the SR FLIVO in-vivo apoptosis kit. The FLIVO was injected intravenously in to nude mice bearing MCF-7 p53 $(+/+)$, MCF-7 p53(-/-),
HCT p53 $(+/+)$ and HCT p53(-/-) tumors post the re-oxygenation therapy. The tissue was extracted and the cells were trypsinized for flow-cytometric analysis of cellular apoptosis. The results showed $74.4 \%$ and $76.1 \%$ apoptosis in the re-oxygenated MCF-7 p53 $(+/+)$ and HCT p53 $(+/+)$ tumors, whereas only $22 \%$ and $24 \%$ apoptosis was observed in the MCF-7 p53(-/-) and HCT p53(-/-) tumors, respectively (Figure $2 \mathrm{~b}$ ). This data established that re-oxygenation induces apoptosis in the hypoxic tumor tissue via a p53-dependent mechanism.

\section{Oxygen enhances p53 transactivation in hypoxic cancer} cells. As $\mathrm{p} 53(+/+)$ tumors are more responsive to oxygeninduced apoptosis, we analyzed the transcriptional activity of p53 in hypoxic and re-oxygenated H1299 cells. Luciferase constructs carrying p53-DBS of 30 p53 downstream gene promoters that are involved in cell-cycle arrest and apoptosis were transfected in $\mathrm{H} 1299$ cells along with wild-type p53 cDNA. The results showed that luciferase activity and thus p53-mediated transcription at these promoters were absent under hypoxic conditions (red bar). On re-oxygenation $(30 \%, 1$ ATA), the luciferase activities were significantly increased (blue bar), and the highest activities were noticed in cell-cycle arrest and DNA-repair genes (Figure 3a). The results suggested that hypoxia-mediated inhibition of p53 downstream genes trans-activation was evoked through re-oxygenation. The expression profiles of genes involved in cellular apoptosis were analyzed both in hypoxic and oxygen-treated MCF-7 cancer cells. Real-time PCR analysis of 84 key genes involved in p53-dependent programmed celldeath was conducted using human Apoptosis $\mathrm{RT}^{2}$ Profiler PCR Array (Figure 3b). The list of genes analyzed is provided in Supplementary Table ST1. The results showed that in hypoxic MCF-7 cells the genes that are involved in cellular apoptosis were switched off (upper panel, green). On the other hand, re-oxygenation showed significant increase in the expression of all the apoptotic genes in the array (lower panel, red). Further, western blot analysis was conducted to compare the expression of major p53-regulated apoptotic proteins in hypoxic and re-oxygenated cancer cells (Figure 3c). The results showed that the expression of p53-regulated bax, apaf-1, puma, bad, bag-1, pig3, bak1, caspase-3, p53 aip-1, pten-10 and tnfsf-10 was very low in hypoxic MCF-7 cancer cells (Figure 3c, lane 2). However, on re-oxygenation there was a substantial increase in the expression of these p53-regulated apoptotic genes (Figure 3c, lane 3).

Re-oxygenation restores p53 wild-type conformation and p53 post-translational modifications. Under stress conditions, Wt-p53 is known to exist in mutant conformation that lacks DNA-binding function. As p53 is known to be transcriptionally inactive under hypoxia ${ }^{16}$ and re-oxygenation showed significant reduction in tumor growth through induction of p53-downstream apoptotic genes, we determined whether oxygen could restore p53 transactivation function in hypoxic core of MCF7 tumor via restoration of its wild-type conformation. The effect of oxygen treatment on the conformational status of p53 under in-vivo conditions was analyzed. The hypoxic core tissues from the hypoxic 
a

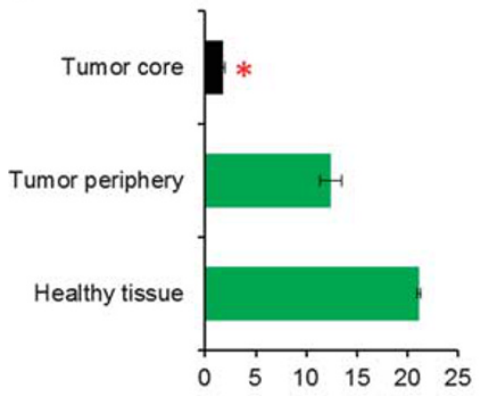

$\mathrm{O}_{2}$ Concentration $(\mathrm{mmHg}$ )

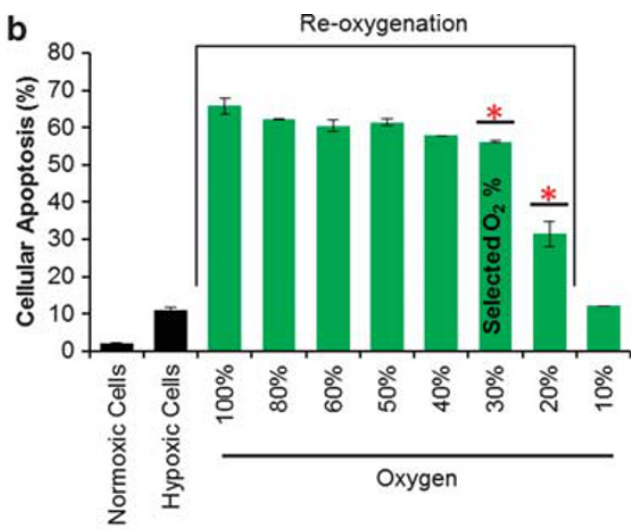

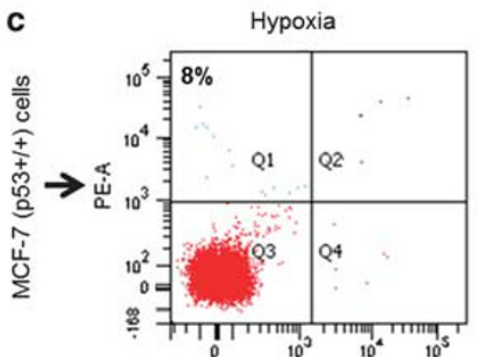
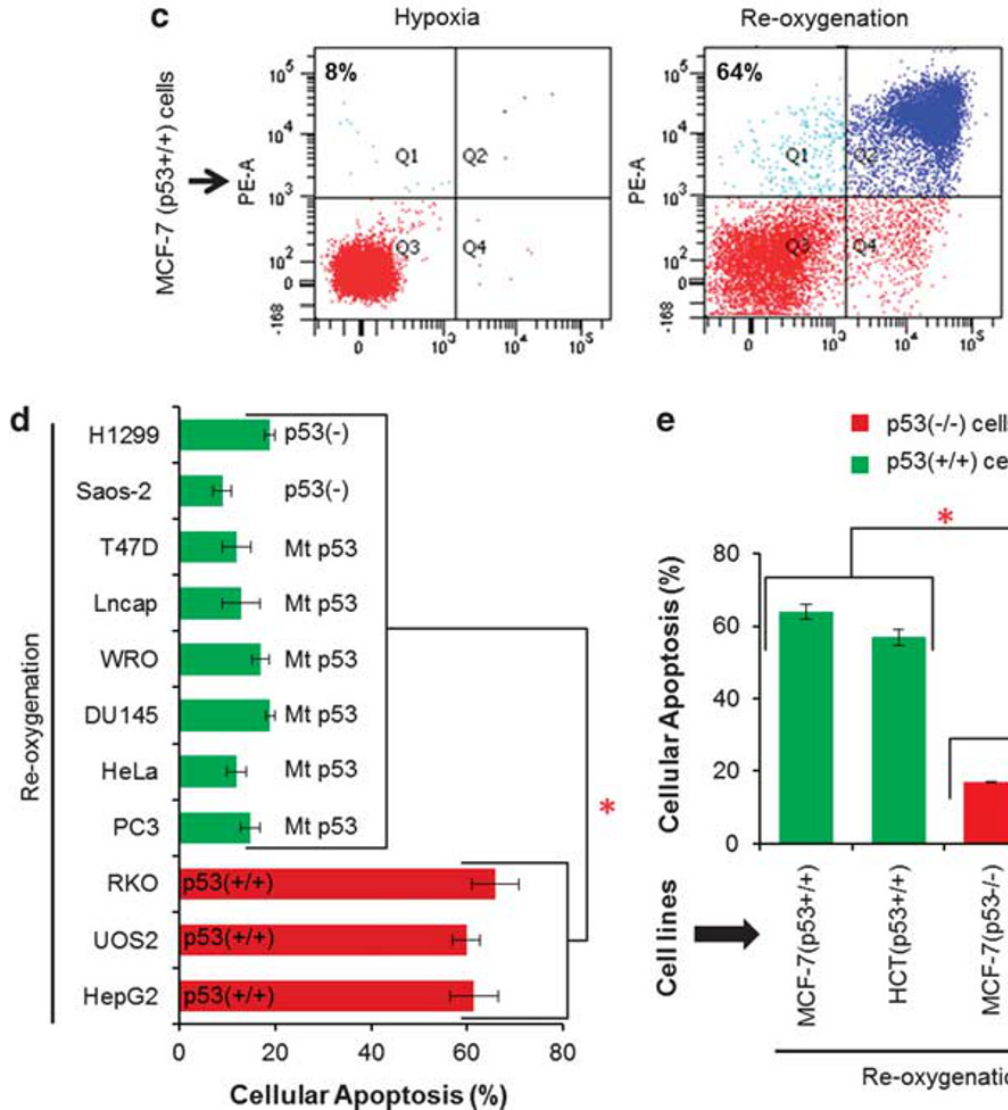

e

p53(-/-) cells

a $\mathrm{p} 53(+/+)$ cells

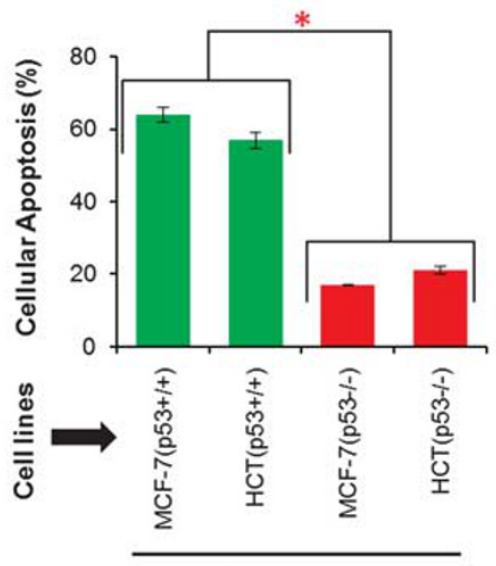

Re-oxygenation

Figure 1 Re-oxygenation induces p53-dependent apoptosis in cancer cells. (a) The oxygen concentration in the peripheral and the core tissue regions of the MCF-7 tumors (approximately $2.2 \mathrm{~cm}^{3}$ ) were analyzed using EPR oximetry. The tumor core tissue shows $1.8 \mathrm{~mm} \mathrm{Hg} \mathrm{pO}$, whereas the peripheral tumor tissue shows $14.2 \mathrm{~mm} \mathrm{Hg}$ $\mathrm{pO}_{2}$. The healthy non-tumor tissue shows $21.2 \mathrm{~mm} \mathrm{Hg} \mathrm{pO}(n=5) .{ }^{1 *} \mathrm{P}<0.0148$. (b) Cellular apoptosis is observed in hypoxic MCF-7 cells, which were re-oxygenated for $24 \mathrm{~h}$ at $10-100 \%$ oxygen concentration. Results show significant apoptotic fraction in hypoxic MCF-7 cells exposed to $30-100 \%$ oxygen $\left(n=10\right.$, S.D., ANOVA). ${ }^{*} P<0.042$. (c) Annexin $V$ staining of hypoxic MCF-7 cells shows significant increase in the apoptotic fraction of the hypoxic MCF-7 cells on re-oxygenation with $30 \%$ oxygen $(n=10)$. (d) The effect of re-oxygenation $\left(30 \% \mathrm{O}_{2}\right)$ is observed on the cellular apoptotic fraction of various cancer cell lines with $\mathrm{p} 53(+1+)$ and $p 53(-1-)$ status. The results show that reoxygenation induces higher apoptosis in cancer cells with wild-type p53 ( $n=10$, S.D., ANOVA). ${ }^{*} P<0.022$. (e) The role of p53 in re-oxygenation-induced apoptosis in hypoxic cancer cells using the MCF-7 p53 $(+/+)$, MCF-7 p53(-I-) and HCT p53 $(+/+)$, HCT p53(-I-) system. The results show that re-oxygenation induces 64 and $57 \%$ apoptosis in MCF-7 p53 $(+I+)$, HCT p53 $(+I+)$ cells. On the other hand a mere 17 and $21 \%$ apoptosis is observed in the MCF-7 p53(-I-), HCT p53(-I-) cells. ${ }^{*} P<0.037$

(control), cisplatin-treated and re-oxygenated MCF-7 tumor xenografts were excised and the p53 wild-type (1620) and mutant (240) conformations were analyzed using IPP with p53 conformational antibodies (Figure 4a). Simultaneously, the ratio of the 1620 and 240 forms of p53 was analyzed in the control, cisplatin-treated and the re-oxygenated MCF-7 p53 $(+/+)$ and HCT p53 $(+/+)$ solid tumors (Figure $4 \mathrm{~b})$. The hypoxic zones of the solid tumors contain p53 in mutant (240) form. Cisplatin treatment was not effective in increasing the 1620 form of p53 whereas re-oxygenation of hypoxic tumors resulted in significant rescue of the p53 1620 form in both MCF-7 and HCT tumors. The results showed that p53 

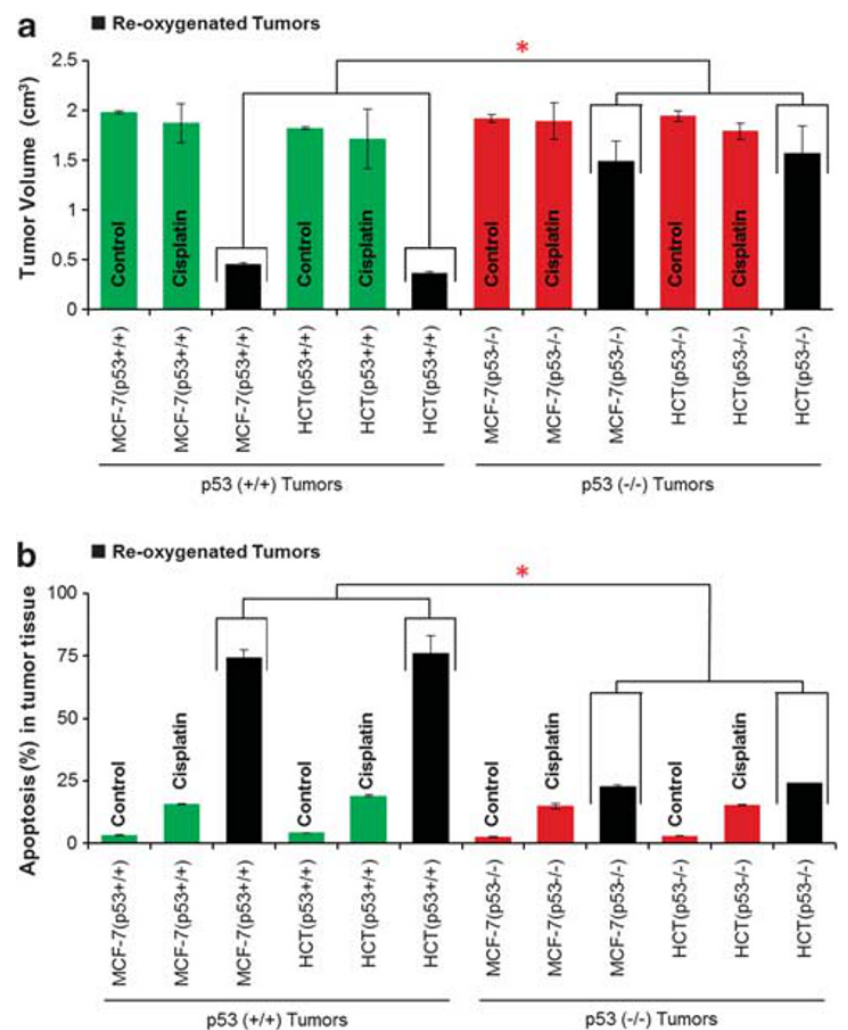

Figure 2 Re-oxygenation induces p53-dependent apoptosis in hypoxic tumors. (a) The volume of hypoxic MCF-7 p53 $(+1+$ ), MCF-7 p53 $(-/-)$, HCT p53 $(+/+)$ and HCT p53(-/-) tumor xenografts is measured after treatment with cisplatin and re-oxygenation. Results show that cisplatin treatment does not cause any significant change in the tumor size. The re-oxygenation treatment induces $>75 \%$ tumor size reduction in both MCF-7 p53 $(+1+)$ and HCT p53 $(+1+)$ tumors. On the other hand, re-oxygenation of MCF-7 p53(-I-) and HCT p53(-l-) tumors led to only 22 and $24 \%$ tumor regression ( $n=8$, S.D., ANOVA). ${ }^{*} P<0.034$. (b) In-vivo apoptosis kit from FLIVO is used to analyze if the re-oxygenation-induced tumor regression is via apoptosis. The results show that re-oxygenation induces $>75 \%$ apoptosis in both MCF-7 p53 $(+I+)$ and HCT p53 $(+I+)$ tumors and only 22 and $24 \%$ in MCF-7 p53(-l-) and HCT p53(-l-) tumors ( $n=8$, S.D. ANOVA). ${ }^{*} P<0.027$

exists in mutant conformation in hypoxic tumors; cisplatin treatment is not effective in restoration of the p53 1620 conformation, however, re-oxygenation alone significantly increased in the wild-type (1620) conformation. Further the role of oxygen in rescue of p53 wild-type conformation in hypoxic cultured $\mathrm{H} 1299$ cells (p53-/-) was analyzed after transfection of Wt p53 cDNA in these cells, using immunoprecipitation (Figure 4c). H1299 cells were cultured in hypoxia chamber for $72 \mathrm{~h}$ and the levels of (1620) and (240) conformation were analyzed. In normoxic conditions, p53 (1620) and p53 (240) forms existed in a near $1: 1$ ration. The brief hypoxia shock of $8 \mathrm{~h}$ stabilized the p53 1620 form. At $54 \mathrm{~h}, \mathrm{p} 53$ was exclusively present in mutant conformation whereas after subjecting the cells to $30 \%$ oxygen (1 ATA) rapid rise in (1620) level and a fall in (240) level were observed. The results suggested that the rise in transcriptionally active $\mathrm{p} 53$ because of re-oxygenation is responsible for induction of p53 downstream genes, and consequently, apoptosis resulting in tumor regression. We then wanted to know whether re-oxygenation might alter the status of p53 phosphorylation and acetylation in inducing p53 transcriptional activity. The analysis of all p53 serine, threonine and lysine residues, which may undergo phosphorylation and acetylation, was conducted through immunoprecipitation using antibodies against phosphorylated Ser $6,9,15,20,33,37,46,315$ and 392 , phosphorylated $\mathrm{Th}^{18,55}$, 81, 155 and 377 and acetylated Lys ${ }^{120,164,305,320,373,379 ~ a n d ~} 382$ residues. Hypoxic MCF-7 cells showed minimal phosphorylation at Ser ${ }^{6,9,15}$ and acetylation at Lys ${ }^{379,} 382$ residues (Figure 4d). On re-oxygenation the profile of p53 post-translational modifications was significantly altered and p53 was phosphorylated and acetylated at all the known Ser, Thr and Lys residues (Figure 4d). This data confirmed that oxygen-induced p53 transcriptional activity and p53 posttranslational modifications may be linked and that oxygenation induces apoptosis in hypoxic cancer cells by rescuing p53 transcriptional activity via alteration of p53 post-translational modification pattern.

\section{Discussion}

In this study, we have shown that normobaric (1 ATA) re-oxygenation $(50 \%$ in vivo and $30 \%$ in vitro) is sufficient to induce apoptosis in various p53 $(+/+)$ and p53(-/-) cancer cells although the response to oxygen was significant in p53 $(+/+)$ cells. p53 $(+/+)$ cells were earlier shown to have better response to chemo- and radiotherapy. ${ }^{17,18}$ In general, hypoxic cells are more resistant to chemo- and radiotherapy treatment than well-oxygenated cells. It was suggested earlier that the abundance of cells at intermediate hypoxia, that is, $\mathrm{pO}_{2} \quad 0.5-20 \mathrm{~mm} \mathrm{Hg}$, causes the resistance of tumors to radiotherapy ${ }^{19}$ although hypoxia and re-oxygenation are necessary for lysyl-oxidase catalytic activity, which was shown to facilitate cancer cell migration through a hydrogen peroxide-mediated mechanism. ${ }^{20}$ Re-oxygenation $(50 \%)$ was shown to regress MCF-7 tumor xenograft (63\%) through the restoration of p53 wild-type conformation which, in turn, caused induction of p53-downstream apoptotic, cell-cycle arrest and DNA-repair genes. Oxygen-mediated p53 conformational change that leads to its transactivation and induction of genes in regression of tumor is an interesting observation in this study.

Re-oxygenation was further responsible for inducing p53 post-translational modifications, which may be the prime cause of p53 trans-activation. It is established that p53 transcriptional activity is dependent on the status of p53 post-translational modifications. ${ }^{20,21}$ Although phosphorylation of $\operatorname{ser}^{6}, \operatorname{ser}^{9}, \operatorname{ser}^{37}, \operatorname{ser}^{46}$ was reported earlier under hypoxic condition, ${ }^{21}$ our results show that there was no phosphorylation of $\operatorname{ser}^{37}$ and $\operatorname{ser}^{46}$ at $1.8 \%$ oxygen, which confirms that p53 phosphorylation is dependent on $\mathrm{O}_{2}$ level in hypoxia. Further, oxygenation plus cisplatin has an edge over oxygenation in regard to the level of rescued p53. In conclusion, normobaric oxygenation at low ATA, in contrast to $\mathrm{HBO}$, with or without chemotherapeutic may be the safest and effective strategy for $\mathrm{p} 53+/+$ tumor regression as oxygen is shown to restore p53 function in hypoxic tumor. Future work would focus on the mechanism of p53 conformational change under deprived oxygen in the hypoxic core of solid tumors. 
a

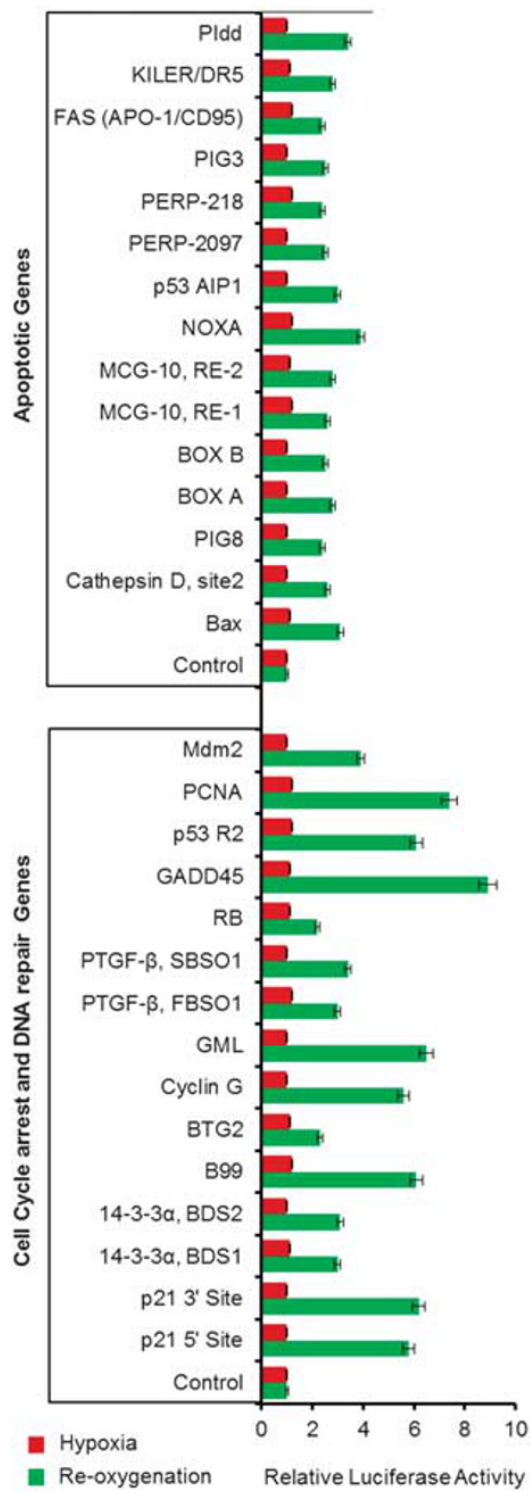

b
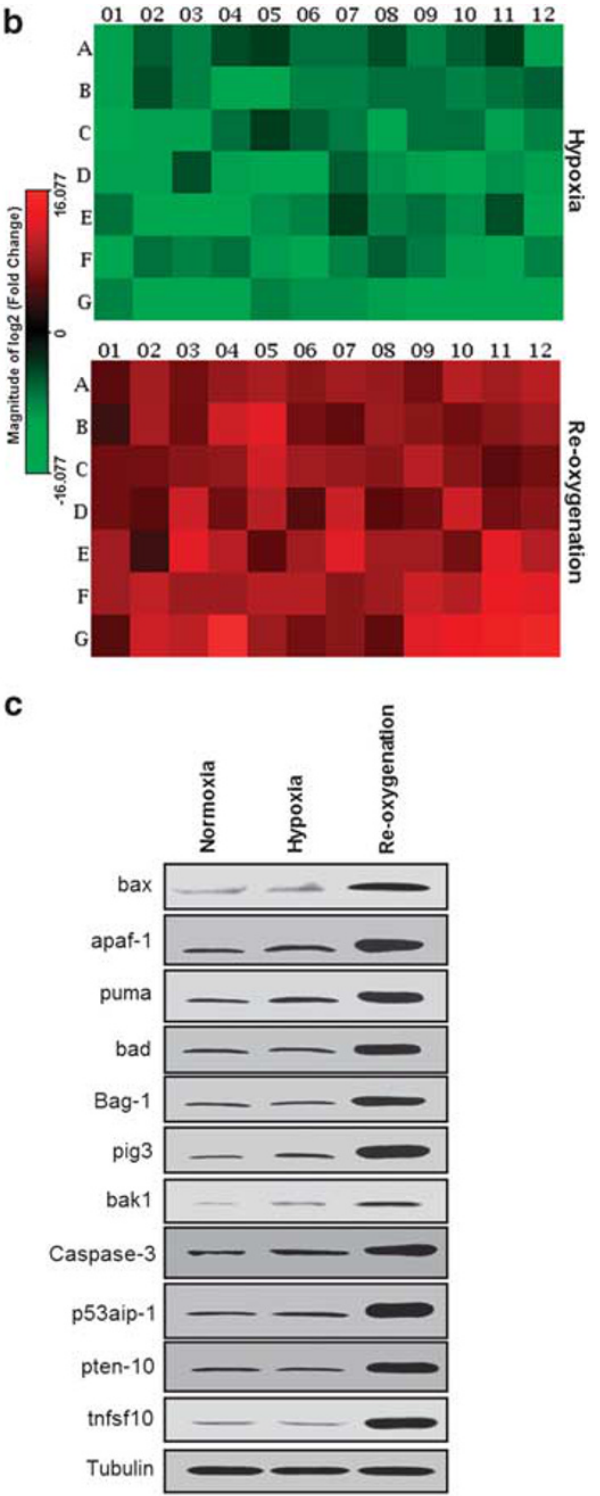

Figure 3 Re-oxygenation increases expression of p53 downstream genes. (a) Hypoxic and re-oxygenated cancer cells were transfected with luciferase cDNA constructs carrying p53 DNA-binding sites. Results show that p53 is unable to increase luciferase activity at the promoters of its downstream genes in hypoxic cancer cells (black bar). On re-oxygenation of the hypoxic cancer cells the luciferase activity of p53 downstream genes is significantly increased (blue bar) ( $n=11$, S.D. ANOVA). (b) Real-time PCR using the apoptotic gene array kit from SA Biosciences (Valencia, CA, USA) shows that p53 downstream apoptotic genes were negatively regulated in hypoxic cancer cells (upper panel). Whereas the expression of these genes was significantly higher in re-oxygenated cancer cells (lower panel) $(n=12)$. (c) Expression of proteins involved in p53 apoptotic pathway bax, apaf-1, puma, bad, bag-1, pig-3, bak-1, caspase-3, p53aip-1, pten-10 and tnfsf10 is analyzed in hypoxic (lane 2) and re-oxygenated (lane 3) cancer cells $(n=10)$. Re-oxygenation-induced significant increase in the expression of these proteins

\section{Materials and Methods}

Cell culture and transfections. HepG2, UOS2, RKO, Saos-2, H1299, PC3, HeLa, DU145, WRO, Lncap, and T47D, MCF-7 and HCT cells lines were obtained from National Centre for Cell Sciences (Pune, India). The cell lines were maintained in DMEM medium supplemented with $10 \%$ FBS. All the transfections were carried out using Effectene transfection reagent (Qiagen, Valencia, CA, USA) according to manufacturer's instructions.

Cell culture for tumor induction. MCF-7, a human breast cancer cell line, was maintained in DMEM/F12 supplemented with $10 \% \mathrm{FBS}$ and $1 \%$ antibiotics. For injection, cell at $70-90 \%$ confluency were trypsinized and re-suspended in serumfree medium with 1:1 Matrigel at a concentration of $1 \times 10^{7} \mathrm{cell} / \mathrm{s} / \mathrm{ml}$ on ice. Cell viability, $>95 \%$, was determined by Trypan blue exclusion assay.
Annexin V staining. Beckton Dickinson (Franklin Lakes, NJ, USA) flow cytometer was used to detect the apoptotic cell surface shift of phosphatidylserine by the binding of fluorescein isothiocyanate (FITC)-conjugated annexin $V$ to the outer membrane of intact cells. Floating cells were collected by centrifugation and these, as well as the attached cells were washed in phosphate-buffered saline (PBS) $\left(\mathrm{Ca}^{2+}\right.$ or $\mathrm{Mg}^{2+}$ free $) / 0.1 \%$ EDTA. The attached cells were gently be scraped off the dish, without trypsin digestion and the floating and attached cell populations were combined, by centrifugation. After centrifugation, the cells were incubated with $500 \mu \mathrm{l}$ binding buffer (Abcam, Cambridge, MA, USA) then $5 \mu \mathrm{l}$ of annexin V-FITC and $5 \mu \mathrm{l}$ propidium iodide was added. Cells were incubated at room temperature for $5 \mathrm{~min}$. These cells were then filtered through $70 \mathrm{~m}$ mesh, to eliminate cell aggregates and analyzed by flow cytometry. 


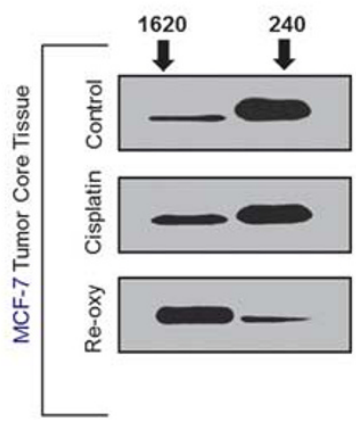

b 1620 Levels $\bullet 240$ Levels

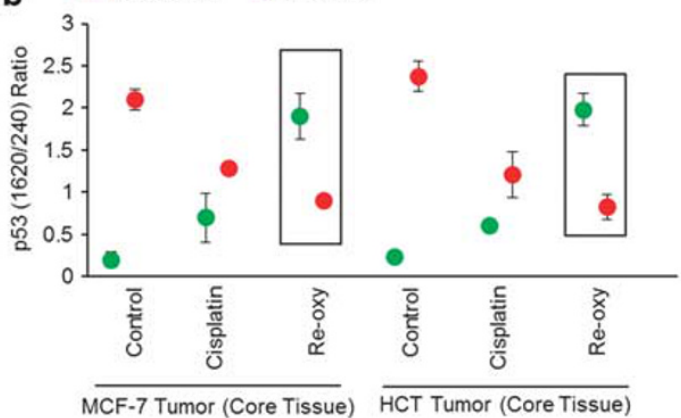

C

H1299 cells + Wt p53 cDNA

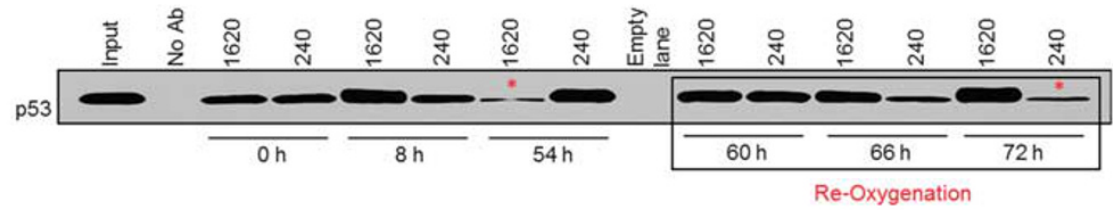

d Hypoxia

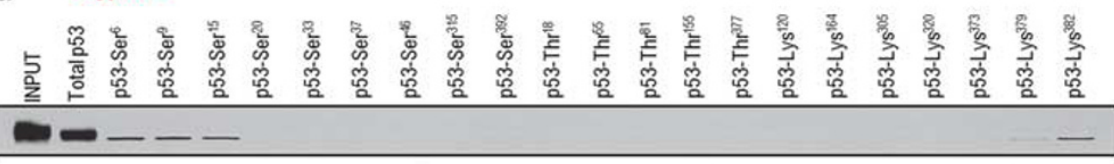

Hypoxia + Re-oxygenation

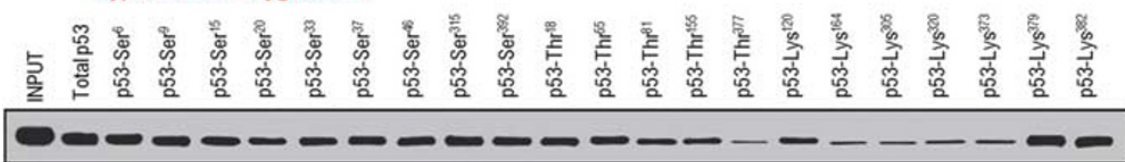

Figure 4 Re-oxygenation increases p53 post-translational modifications. Re-oxygenation converts mutant p53 to wild-type p53. (a) The p53 wild-type and mutant conformation were analyzed in hypoxic core tissue of control and treated MCF-7 tumor xenografts. Results show that p53 exists in a mutant conformation in hypoxic tumors. Cisplatin treatment is not effective in restoration of p53 (1620) conformation in the hypoxic zones of the solid tumors. On re-oxygenation of the tumors the wt p53 conformation showed a significant increase, and higher rate of the conversion of mutant p53 to wt p53 $(n=7)$. (b) The ratio of p53 1620 and p53 240 form was analyzed in the hypoxic core tissue of MCF-7 p53 $(+/+)$ and HCT p53 $+(+)$ tumors using in-vivo ELISA. The results show that re-oxygenation improves the p53-1620/p53-240 ratio and helps in synthesis of p53 1620 form. (c) The effect of re-oxygenation on the conversion of mt p53 to wt p53 is observed in hypoxic H1299 cells transfected with Wt p53 cDNA. IPP showed that at $0 \mathrm{~h}$ (i.e. normoxia) p53 1620 and p53 240 form are present in equal ration (lanes 3 and 4). After a brief hypoxic shock of $8 \mathrm{~h}$, the p53 1620 form is stabilized (lanes 5 and 6). After a chronic hypoxia exposure of $54 \mathrm{~h}$, the p53 1620 conformation is lost and p53 exists as 240-conformation (lanes 7 and 8 ). MCF-7 cells are re-oxygenated after $54 \mathrm{~h}$ of hypoxia and $6 \mathrm{~h}$ after re-oxygenation (60-h mark) p53 conformation is revived and IPP showed increase in 1620 form (lane 3). p53 wild-type conformation showed

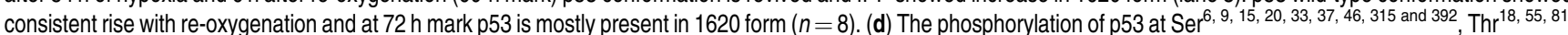

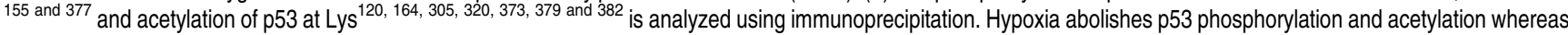
re-oxygenation induces phosphorylation and acetylation at p53 core domain along with $\mathrm{p} 53 \mathrm{~N}$ and $\mathrm{C}$ termini $(n=7)$

EPR oximetry. LiNc-BuO microcrystals ${ }^{22}$ were used for tissue oxygen measurements. LiNc-Buo microcrystals $(10 \mu \mathrm{g})$ were suspended in $500-\mu \mathrm{l}$ DMEM. A $25-\mu$ l aliquot of this suspension was added to $10^{5}$ MCF-7 cells for each 100- $\mu$ linjection. Oxygen measurements were performed immediately, weekly, and on killing using an L-band EPR spectrometer (Magnettech, Berlin, Germany). EPR spectra were acquired as single 30-s scans. The instrument settings were as follows: incident microwave power, $4 \mathrm{~mW}$; modulation amplitude, $180 \mathrm{mG}$; modulation frequency, $100 \mathrm{kHz}$; receiver time constant, $0.2 \mathrm{~s}$. The peak-to-peak width of the EPR spectrum was used to calculate $\mathrm{pO}_{2}$ using a standard calibration curve, as reported. ${ }^{22}$

Animal and diet. Separate batches (for eight separate experiments) of $\mathrm{BALB} / \mathrm{c}$ nu/nu, athymic mice ( $n=10$ per experiment, aged 5 to 6 weeks old) were maintained in micro-isolator cages (2 per cage) within a pathogen-free isolation facility with 12 -h light-dark cycle at 22 to $24{ }^{\circ} \mathrm{C}$ and $50 \%$ humidity. The basal diet (BD) was based on the AIN-93G formulation, modified to have a high fat content ( $20 \%$ corn oil) at the expense of corn starch. The FS diet was the BD supplemented with $10 \%$ freshly ground FS corrected for the contribution of FS to fat, fiber and protein components so that the energy values of the diets were maintained.

Tumor induction. A $80-\mu$ l cell suspension containing $1 \times 10^{7}$ cells was subcutaneously injected into the hind legs of each mice, thus producing two sites of MCF-7 tumor per mouse. Tumor volumes were monitored weekly by calliper measurement of the length, width and height and were calculated using the formula for a semi-ellipsoid $\left(4 / 3 \pi r^{3} / 2\right)$. After 3 weeks, mice bearing tumors with volumes averaging approximately $200 \mathrm{~mm}^{3}$ were randomized for treatment. As a result of the variations in tumor take and initial tumor growth as well as the removal of mice for analysis at various time points, the number of mice at each time point varied from experiment to experiment. The number of mice analyzed is reported in the text.

Tumor regression. The size of the tumors were carefully monitored after the treatments using vernier calliper measurement of the length, width and height and were calculated using the formula for a semi-ellipsoid $\left(4 / 3 \pi r^{3} / 2\right)$. 
Apoptosis in tumor samples. The cellular apoptosis in the tumors showing regression on re-oxygenation was measured using Red SR FLIVO in-vivo apoptosis staining kit (Immuno Chemistry Technologies USA, Bloomington, MN, USA) with flow-cytometry analysis.

Protein ELISA. The wells of a PVC microtiter plate were coated with polyclonal antibodies at a concentration of $1-10 \mu \mathrm{g} / \mathrm{ml}$ in carbonate/bicarbonate buffer (pH 7.4). The plate was covered with an adhesive plastic and incubated overnight at $4^{\circ} \mathrm{C}$. Next, the coating solution was removed and the plate was washed twice by filling the wells with $200 \mu \mathrm{l}$ PBS. The solutions or washes were removed by flicking the plate over a sink. The remaining drops were removed by patting the plate on a paper towel. The remaining protein-binding sites in the coated wells were blocked by adding $200 \mu \mathrm{l}$ blocking buffer, $5 \%$ non-fat dry milk/PBS, per well. Again the plate was covered with an adhesive plastic and incubated overnight at $4{ }^{\circ} \mathrm{C}$. In all, $100 \mu \mathrm{l}$ of appropriately diluted cell suspension was added to each well and incubated for $90 \mathrm{~min}$ at $37^{\circ} \mathrm{C}$. In total, $100 \mu \mathrm{l}(0.5 \mu \mathrm{g} / 100 \mu \mathrm{l})$ of diluted detection antibody (monoclonal) was added to each well. The plate was covered with an adhesive plastic and incubated for $2 \mathrm{~h}$ at room temperature. The plates were washed four times with PBS and $100 \mu \mathrm{l}$ of secondary antibody conjugated with horseradish peroxidase was added to the plate The plate was covered with an adhesive plastic and incubated for $1-2 \mathrm{~h}$ at room temperature. The plate was washed four times with PBS.

Preparation of lysates from tumor xenografts. The tissue of interest was dissected with clean tools, on ice preferably and as quickly as possible to prevent degradation by proteases. The tissue was placed in round bottom microfuge tubes and was 'snap-freezed' by immersing it in liquid nitrogen. The samples were stored at $-80^{\circ} \mathrm{C}$ for later use or kept on ice for immediate homogenization. In all, $300 \mu$ l of lysis buffer was rapidly added to the tube for a $5 \mathrm{mg}$ piece of tissue and homogenized with an electric homogenizer. The blade was rinsed twice with another $300 \mu$ lysis buffer. The samples were then maintained at constant agitation for $2 \mathrm{~h}$ at $4{ }^{\circ} \mathrm{C}$. The samples were centrifuged for $20 \mathrm{~min}$ at 12000 r.p.m. at $4^{\circ} \mathrm{C}$ in a micro-centrifuge. The tubes were gently removed from the centrifuge and placed on ice, the pellet was discarded and the supernatant was aspirated and placed in a fresh tube kept on ice.

Luciferase assay. Cells were plated in $35 \mathrm{~mm}$ Petri dishes the day before transfection so that they reached $60-80 \%$ confluence on transfection. Reporter plasmids (carrying p53 downstream genes DBS in PGL2 vector (1.0-1.5 mg per well) were transfected with effectene transfection reagent (Qiagen) as per the manufacturer's instructions. After desired incubation period, the cells were washed in cold PBS three times and lysed with $200 \mathrm{ml}$ of the lysis buffer by a freeze-thaw cycle, and lysates were collected by centrifugation at 14000 r.p.m. for $2 \mathrm{~min}$ in a bench top centrifuge. Twenty micro-liter of supernatant was used for the assay of luciferase activity using a kit (Promega, Madison, WI, USA) as per the manufacturer's instruction.

Human apoptosis PCR array. The Human Apoptosis $\mathrm{RT}^{2}$ Profiler PCR Array kit (PAHS-012) was used to profile the expression of 84 key genes involved in programmed cell death.

Immunoprecipitation. To assay the p53 conformation in treated cells, the cells and the tissue samples were washed three times in ice-cold PBS and lysed in $500 \mu \mathrm{l}$ (per 10-cm-diameter dish) of NP-40 lysis buffer (100 mM NaCl, $100 \mathrm{mM}$ Tris (pH 8.0), 1\% NP-40) supplemented with proteasome inhibitors (Complete inhibitor mix; Boerhinger Mannheim, Ridgefield, CT, USA) for $30 \mathrm{~min}$ at $4{ }^{\circ} \mathrm{C}$. p53 protein was immunoprecipitated overnight at $4^{\circ} \mathrm{C}$ by incubation with PAb240 and PAb1620-protein A-Sepharose beads equilibrated in NP-40 lysis buffer. The immunoprecipitated protein was washed three times with NP-40 lysis buffer, and samples were re-suspended in $50 \mu$ of $2 \times$ sodium dodecyl sulfate (SDS) sample buffer, incubated at room temperature for $10 \mathrm{~min}$ and then assayed by SDS-10\% polyacrylamide gel electrophoresis. Western blots were probed with either antip531801 or anti-p53421 antibodies. Additionally, western blot analysis to assess p53 protein levels in whole-cell extracts was performed in parallel using PAb1801.

Western blotting. Whole-cell lysates were prepared using RIPA buffer (10 mM Tris-HCl (pH 7.4), $150 \mathrm{mM} \mathrm{NaCl}, 1 \%$ NP-40, 1 mM EDTA, $0.1 \%$ SDS, and $1 \mathrm{mM}$ DTT). Proteins were resolved by $10 \%$ or $12 \%$ SDS-PAGE and transferred onto PVDF membranes (Invitrogen, Grand Island, NY, USA). Incubations with primary antibodies were followed by incubations with the appropriate secondary antibodies (Amersham, Piscataway, NJ, USA) and detection by DAB substrate development kit from (Vector Lab, Burlingame, CA, USA). To quantify western

blotting signals, densitometry was performed using the software Image $(\mathrm{NIH}$, Bethesda, MD, USA)

\section{Conflict of Interest}

The authors declare no conflict of interest.

Acknowledgements. This research work was partially supported by UGCCB, JNU (LRE) and NIH EB004031 grants.

1. Daruwalla J, Christophi C. Hyperbaric oxygen therapy for malignancy: a review. World J Surg 2006; 30: 2112-2131.

2. Gill $A L$, Bell CN. Hyperbaric oxygen: its uses, mechanisms of action and outcomes. QJM Mon J Assoc Phys 2004; 97: 385-395.

3. Gothard L, Haviland J, Bryson P, Laden G, Glover M, Harrison S et al. Randomised phase II trial of hyperbaric oxygen therapy in patients with chronic arm lymphoedema after radiotherapy for cancer. Radiother Oncol J Eur Soc Therapeutic Radiol Oncol 2010; 97: 101-107.

4. Stuhr LE, Raa A, Oyan AM, Kalland KH, Sakariassen PO, Petersen K et al. Hyperoxia retards growth and induces apoptosis, changes in vascular density and gene expression in transplanted gliomas in nude rats. J Neuro-Oncol 2007; 85: 191-202.

5. Selvendiran K, Kuppusamy ML, Ahmed S, Bratasz A, Meenakshisundaram G, Rivera BK et al. Oxygenation inhibits ovarian tumor growth by downregulating STAT3 and cyclin-D1 expressions. Cancer Biol Ther 2010; 10: 386-390.

6. Chavko M, Xing G, Keyser DO. Increased sensitivity to seizures in repeated exposures to hyperbaric oxygen: role of NOS activation. Brain Res 2001; 900: 227-233.

7. Plafki C, Peters P, Almeling M, Welslau W, Busch R. Complications and side effects of hyperbaric oxygen therapy. Aviat Space Environ Med 2000; 71: 119-124.

8. Erkkila K, Pentikainen V, Wikstrom M, Parvinen M, Dunkel L. Partial oxygen pressure and mitochondrial permeability transition affect germ cell apoptosis in the human testis. J Clin Endocrinol Metabol 1999; 84: 4253-4259.

9. Sermeus A, Michiels C. Reciprocal influence of the p53 and the hypoxic pathways. Cell Death Disease 2011; 2: e164.

10. Kim BM, Choi JY, Kim YJ, Woo HD, Chung HW. Reoxygenation following hypoxia activates DNA-damage checkpoint signaling pathways that suppress cell-cycle progression in cultured human lymphocytes. FEBS Lett 2007; 581: 3005-3012.

11. Shenberger JS, Dixon PS. Oxygen induces S-phase growth arrest and increases p53 and p21(WAF1/CIP1) expression in human bronchial smooth-muscle cells. Am J Resp Cell Mol Biol 1999; 21: 395-402.

12. Gogna R, Madan E, Kuppusamy P, Pati U. Chaperoning of mutant $p 53$ protein by wild-type p53 protein causes hypoxic tumor regression. J Biol Chem 2012; 287: 2907-2914.

13. Weinmann M, Jendrossek V, Guner D, Goecke B, Belka C. Cyclic exposure to hypoxia and reoxygenation selects for tumor cells with defects in mitochondrial apoptotic pathways. FASEB J Off Pub Federation Am Soc Exp Biol 2004; 18: 1906-1908.

14. Moulder JE, Rockwell S. Tumor hypoxia: its impact on cancer therapy. Cancer Metast Rev 1987; 5: 313-341.

15. Gogna R, Madan E, Kuppusamy P, Pati U. Reactive oxygen species-mediated p53 coredomain modifications determine apoptotic or necrotic death in cancer cells. Antioxidants Redox Signal 2012; 16: 400-412.

16. Achison M, Hupp TR. Hypoxia attenuates the p53 response to cellular damage. Oncogene 2003; 22: 3431-3440.

17. Gudkov AV, Komarova EA. The role of $p 53$ in determining sensitivity to radiotherapy. Nat Rev Cancer 2003; 3: 117-129.

18. Steelman LS, Martelli AM, Nicoletti F, McCubrey JA. Exploiting p53 status to enhance effectiveness of chemotherapy by lowering associated toxicity. Oncotarget 2011; 2: 109-112.

19. Wouters BG, Brown JM. Cells at intermediate oxygen levels can be more important than the 'hypoxic fraction' in determining tumor response to fractionated radiotherapy. Radiation Res 1997; 147: 541-550.

20. Postovit LM, Abbott DE, Payne SL, Wheaton WW, Margaryan NV, Sullivan R et al. Hypoxia/reoxygenation: a dynamic regulator of lysyl oxidase-facilitated breast cancer migration. J Cell Biochem 2008; 103: 1369-1378.

21. Meek DW, Anderson CW. Posttranslational modification of $\mathrm{p53}$ : cooperative integrators of function. Cold Spring Harbor Perspect Biol 2009; 1: a000950.

22. Pandian RP, Parinandi NL, Ilangovan G, Zweier JL, Kuppusamy P. Novel particulate spin probe for targeted determination of oxygen in cells and tissues. Free Radical Biol Med 2003; 35: 1138-1148

(c)

MERIGHIS licensed under the Creative Commons Attribution-Noncommercial-No
Derivative Works 3.0 Unported License. To view a copy of this license, licensed under the Creative Commons Attribution-Noncommercial-No
Derivative Works 3.0 Unported License. To view a copy of this license, visit http://creativecommons.org/licenses/by-nc-nd/3.0/
Cell Death and Disease is an open-access journal published by Nature Publishing Group. This work is 